\title{
A Pedagogical Perspective on Promoting English as a Foreign Language Writing through Online Forum Discussions
}

\author{
Jayaron Jose ${ }^{1} \&$ Mohammed Jafre Zainol Abidin ${ }^{1}$ \\ ${ }^{1}$ School of Education, University of Science Malaysia (USM), Malaysia \\ Correspondence: Jayaron Jose, School of Education, Univeristy of Science Malaysia, 11800, Gelugor, Penang, \\ Malaysia. Tel: 00968-92132-495. E-mail: jayaronjose@gmail.com
}

Received: October 18, 2015 Accepted: January 8, 2016 Online Published: January 10, 2016

doi: $10.5539 /$ elt.v9n2p84

URL: http://dx.doi.org/10.5539/elt.v9n2p84

\begin{abstract}
Use of educational technologies has become increasingly significant in the field of English Language Learning. Both the teachers and students are dependent on Information and Communication Technology (ICT) and its different tools for teaching and learning in particular, and socialization in general. The scope and significance of the study on the use of ICT tool such as online discussion forum in facilitating English as a foreign language teaching and learning therefore is quite relevant considering its potential in exchanging information using the target language (L2). The study included 56 participants $(N=56)$ at post-foundation level from Al Musanna College of Technology in Oman with the objective to find out the effectiveness of online forum discussions on the learners' EFL (English as a Foreign Language) writing performance in terms of its linguistic complexity. The experimental group $(N=28)$ was involved in synchronous online forum discussion, and the control group $(N=$ 28) was engaged in asynchronous blog writing for a period of one semester. Pre-test and posttest were administered to collect quantitative data, and the participants of the experimental group were interviewed to collect the qualitative data. The post-test analysis of the quantitative data found no significant $(p=0.05)$ statistical difference between the groups' writing performance in terms of linguistic complexity. However, the analysis of the qualitative data collected through interview found that the use of online forum discussion in facilitating EFL writing has much positive effect on the learning process. The findings, discussion and recommendations are included in this article.
\end{abstract}

Keywords: ELT, online forum discussion, EFL, synchronous, asynchronous, writing, pedagogical

\section{Introduction}

With technological advancements, many ICT platforms (tools) such as different chat platforms, blogs, threaded discussions, etc. have come into existence to promote online discussion among participants. Facebook, WhatsApp., Instagram, etc. are examples of the latest ICT tools or platforms in carrying out discussions in written forms. Online Forum Discussions (OFDs) are considered as 'heart of the course' (Kelly, 2014), and these discussion forums not only promote learner-to-learner interaction, but also between learners and teachers. OFDs establish learners' community and connections, facilitates critical, cognitive thinking and writing skills, enhances learners' explorative learning by going through others' work exposing them to diverse ways of learning and it encourages the learners to express their ideas more comfortably than a face-to-face learning situation ("Using Online Discussion”, 2011). OFDs are conducted synchronously and asynchronously to meet the learners' social, academic and future professional needs according to varying learning and communicative situations. The significant growth and influence of ICT in education, and the learners' need to interact with each other through different ICT tools emphasize the importance and scope for incorporating synchronous online forum discussion in English as foreign language (EFL) writing.

\section{Definition of Synchronous and Asynchronous Communication in ICT}

The modern day concept of learning in the context of ICT integration can be categorized into three types of learning. Chao, Hung, and Chen (2012) described them as traditional learning, asynchronous online learning and synchronous online learning. The learning through real-time interaction among learners themselves, and between learners and teachers using wikis, forums and chats is referred as Synchronous learning. Asynchronous learning can be defined as online learning situation where learners can complete their learning on their own space and time or within the time frame set by the teacher using blogs, forums, emails or other ICT tools where participants 
do not receive quick feedback from their peers or their teachers. The face-to-face teaching and learning without any ICT incorporation is referred as traditional learning. The following sections explain the synchronous and the asynchronous communications to understand the meaning of synchronous and asynchronous learning.

\subsection{Asynchronous Communication}

Asynchronous communication is one of the important methods of educational ICT interaction (Johnson \& Aragon, 2003). Such types of asynchronous communication take place in a delayed time, not in the real time (Johnson, 2008). Any-time access, helpful to different learning styles, no classroom pressure and increased interaction are some of the merits of ICT tools (Oztok, Zingaro, Brett, \& Hewitt, 2012). The features and principles of constructivism such as meaningful learning out-put, and collaborative learning are incorporated in asynchronous courses/tasks (Cavana, 2009; Gold, 2001). Other advantages of asynchronous interaction are the opportunity for extra thinking time in threaded discussions, and effective contribution to the discussion and more time for task (Oztok et al., 2012; Cavana, 2009). Learning Management Systems (LMSs) such as Blackboard, WebCT and Moodle are effectively used for asynchronous (or synchronous) communication in language learning (Teng, Chen, Kinshuk, \& Leo, 2012). According to Teng et al. (2012) a few studies were carried out about the students' learning in asynchronous ICT integration especially about the effects of ICT tools on the learners' writing skills. The quasi-experimental study by Hirotani (2009) is an example of synchronous and asynchronous use of ICT tools such as MSN messenger and bulletin board or forum. Though the focus of the study was on the effect of ICT tools on the learners' oral proficiency, it recommended for investigating the use and effects different ICT tools on varying foreign language learning conditions and skills such as writing.

\subsection{Synchronous Communication}

Johnson (2008) defines synchronous communication by its unique feature of real-time interaction among the learners through textual communication (writing). The study by Teng et al. (2012) found the importance of synchronous communication that it has better social intimacy, interaction and presence. The researchers recorded that the written synchronous interaction contributes to "(1) effective interactions among learners, instructors, and course content; (2) complementary use of synchronous/asynchronous resources and tools; and (3) instructional design and facilitation in synchronous cyber classroom settings" (p. 928). The researchers found that synchronous communication helps "continuity and convenience" of classroom interaction and maintains contact (Hou\& Wu, 2011). ICT Synchronous communication through multiple ICT tools (chats, forums, etc.,) therefore can be effectively used for language learning due to its potential for creating a strong sense of a community belonging, social interaction and presence (Shwarz \& Asterhan, 2011) through writing online. For example, online synchronous learning such as Online Forum Discussions is considered a relevant method of language learning in terms of writing in the ever-growing ICT context (Hastie, Hung, Chen, \& Kinshuk, 2010) as it involves electronic writing.

\section{Definition of OFD as a Synchronous Communication Tool}

Online Forum refers to any online 'bulletine board' which is used by the participating writer to post or write his/her comments or opinion on a given topic expecting other participant to post their comments in response to what has been posted first (Rouse, 2011). According to Beal (2010) Online Forum Discussions are 'areas where one can write and read posts from others in the forum with common interests; and the discussion is usually carried out in an ordered thread lay-out focusing on a specific topic in writing. The forum participants can write their opinions, respond to others' messages and discuss relevant issues, and such online interactive communications are called as forums, online forums or online discussion forums (Beal, 2010), which enable participants to engage in informal and formal interaction (Chang, 2012).

Boyle and Nicole (2003) and Bangert (2004) mention that active learning is promoted through online forum discussions while the students engage themselves in discussions; the learners participate in the discussion or conference, debating, describing and asking by being a part of learning group. According to Graham, Cagiltay, Lim, Craner \& Duffy (2003), the learners participating in OFD should be given clear instructions making sure maximum collaboration among learners; the administering of OFDs should involve all forum members of the learners and the discussion should be topic/task oriented. Harris and Sandor (2007) found that the forum discussions are more time effective for instructions and pedagogically sound. Considering the importance of learner interaction and collaboration in the teaching and learning process and the increased acceptance of student centered learning techniques and activities in education, the need for the development of OFDs to motivate learners to participate in their learning has attracted much attention of educators and the stake holders (Boud \& Lee, 2005; Kear, 2004). OFDs therefore set a platform for student-to-student interaction, collaboration and learning (Kear \& Heap, 2007). 
Recent studies (Kim, 2012; Shaw, 2012) on the use of OFDs found that the number of groups and learners affect the discussions. More effective interaction is possible with small group of online discussion participants. Moreover, the teacher's instructions and general guideline influence the discussion in encouraging the participants to involve more in the discussion. According to Xia, Fielder and Siragusa (2013), OFDs are important means of promoting students-to-students interaction and collaborative learning through writing in the context of emerging Information and Communication Technology (ICT). The principles of cooperative learning and constructivism in acquiring knowledge can be best employed in the learning process using online forum discussions (Miyazoe \& Anderson, 2010). Scherer-Bassani (2011) suggests that the teachers should ensure that the students are engaged productively in purposeful discussions while engaging in OFDs avoiding the participants' non-participation and passiveness. The learning tasks or program integrating OFDS should be carefully planned and administered so that the students are encouraged to involve in positive and productive discussions, and the participants should be educated about the significance of the use of OFDs and their positive impact on their linguistic proficiency in real-life (Rovai, 2007). Dixson (2012) mentioned that online instructions or learner participation in online activities are as effective as face-to-face instruction; it requires collaborative learning and strong teacher (instructor) presence.

The above summarized review of literature highlights the significance of ICT tools in learning in general and writing in particular as synchronous and asynchronous OFDs are carried out through writing online in the target language.

\section{Asynchronous Blogs and Synchronous Online Forum Discussions on Moodle}

Blogs and Forums are effective electronic tools for promoting online EFL writing. Moodle (Modular Object Oriented Dynamic Learning Environment) is an open-source Learning Management System (LMS) (moodle.org) that mediates textual comments, discussions and interaction facilitating academic opportunities for exploring different learning and teaching methods through networking among the enrolled (registered) learners (Costa, Alvelos, \& Teixeira, 2012; Cole \& Foster, 2008). The Moodle, as an effective and widely used Learning Management System (LMS) across educational institutions, facilitates the interaction of students through asynchronous (individual blogs) and synchronous (real-time forum discussion) communications.

Some early studies on forums (Savignon \& Rothmeier, 2004; Fitze, 2006) also showed the possibilities of Moodle forum discussions on the language learning process. Miyazoe and Anderson (2012) found that forum discussion and blogs on Moodle platforms as effective ICT tools for promoting writing skills, and the study concluded that its encouraging findings about the positive effects of forums and blogs on the language learning emphasized that more specific studies would shed much light on the appropriateness of the use of these tools in future studies. One of the latest studies on the use of Moodle (Costa et al., 2012) 'observed that the most used materials' formats that respondents access/post are 'Texts"' (p. 340), and it therefore stresses on the significance of Moodle in promoting writing in different forms of texts through online discussion, blogs, etc.

\section{An Action Research on Online Forum Discussion in an Arab EFL Context}

The writer has undertaken a study among Omani EFL learners at tertiary (college) level to get a better insight into the effectiveness of using OFD for teaching and learning EFL (English as Foreign Language) writing. The need for the study was felt due to the teachers' and the students' increased use of technological devices in the college. Moreover, the review of literature on the pedagogical significance of using ICT in teaching and learning especially for language learning in terms of EFL writing also prompted the researcher to undertake the study. In addition, the lack of sufficient research in the field also caused the researcher to carry out the study. Al Aufi and Al Azri (2013) mentioned that sufficient studies on the effectiveness of ICT in language teaching and learning were not carried out in Oman; and as a result, teachers and learners, stake holders are not informed of its effectiveness. The use of ICT tools such OFDs can enhance the learners' exposure to information and interaction; and it would help the learners and teachers to realize the potential and shortfalls of ICT use in learning especially in the field of English Language Teaching (ELT). A study therefore is significant in terms of the effectiveness of using ICT tools such as OFDs in ELT especially in EFL Writing.

Moodle as a Learning Management System (LMS) at Al Musanna College of Technology, Oman was utilized as a platform for carrying out the study. The experimental study made use of tools such as blogs and forums on Moodle for the research.

\subsection{Research Objective and Questions}

The study was undertaken among Omani adult learners with the objective to find out the effectiveness of using the OFDs in EFL written output in terms of linguistic complexity. Research questions were formed based on the 
objective.

\subsection{Research Questions}

In line with research objective the following main question was formed.

Question 1. Is there a statistically significant difference between the linguistic complexity in the EFL written outputs of the experimental group (OFD group) and the control group (Blog Group)?

To answer the above question, the following sub-questions were formed.

1) Is there a significant difference in the lexical diversity between the written outputs of the OFD group and the blog group?

2) Is there a significant difference in the lexical density between the written outputs of the OFD group and the blog group?

3) Is there a significant difference in the syntactic complexity between the written outputs of the OFD group and the blog group?

(The constructs or the variables in the study are theoretically and operationally defined under the section 'Test instruments' in this paper.)

Question 2. What are learners' perceptions towards the Online Forum Discussion?

\subsection{Hypothesis}

Null-hypotheses as shown below are formed to test the significance of the difference between the treatment group and the control group.

1) There is no significant difference in the lexical diversity between the written outputs by the OFD group and the blog group.

2) There is no significant difference in the lexical density between the written outputs by the OFD group and the blog group.

3) There is no significant difference in the syntactic complexity between the written outputs by the OFD group and the blog group.

\subsection{Methodology and Study Design}

A quazi-experimental research design was initiated. The participants were registered in a Moodle mediated for technical communication course coded as ENGL2100. The course focused more on technical writing. The Forum tool on the Moodle was used for the experimental group for synchronous online discussions, and its blog format (Appendix D) was used for the control group for asynchronous blog writing. Ten different topics were displayed on the e-learning page for the participants to discuss/write electronically as instructed by the teacher (Appendix C). The writing topics were relevant to the learners' social and academic context which promoted argumentative writing in English. The topics were selected from the pool of topics that was used for the writing course. For instance, the learners were asked to discuss or write electronically through forum and blog about "Women working in Oman", "the need for Sport Opportunities for students in Omani Colleges", "Using Mobile-phones in classrooms", etc.

Fifty -six participants from two different sections were randomly selected for the study. The participants were grouped by the college administration at the time of their admission to the course, and the researcher did not change their group. Each group consisted of 30 participants. Data from four participants were not used for the analysis because of their irregular participation in the study. All the participants were native speakers of Arabic pursuing their EFL Writing Course at Diploma level. The experiment lasted for a period of one semester consisting 10 weeks. The experimental group was engaged in synchronous online forum discussions on Moodle, and the control group was engaged in asynchronous blog writing on the Moodle.

A writing pretest was conducted before the commencement of the study for both the groups - treatment (OFD) group and control (Blog) group. The test followed the Level Exit Exam (LEE) format recommended by the college. The test includes a topic about which the learners should write an argumentative essay of 300 words. The essay should be organized into paragraphs with arguments and counter arguments with suitable examples. The argumentative essay writing of the LEE was considered quite relevant to the study as the topic-oriented online forums discussions were also argumentative in nature in expressing the learners' opinions on the given topics, and the written output would serve as the quantitative data of the study for analysis in terms of the research objective and questions (Appendix E). The pretest data was collected for analysis. Both groups were 
given two week training in using the OFD and the blog for writing in English. From third week onwards, the treatment was formally begun for a period of 8 weeks on Thursdays for the OFD group and Wednesdays for the Blog group. The students were taken to the pre-booked computer labs at the center, and the lab technicians were present for rectifying any technical issues in using computer systems. At the end of the $8^{\text {th }}$ week, a posttest was conducted and the data from both the group were collected, quantified them into numerical data (Appendix A \& B) and analyzed them using SPSS (2.0). The data was subjected to an inter-rater reliability test with the help of an EFL lecturer. Finally, the data were interpreted and recommendations were made.

In addition to quantitative data, qualitative data was also collected to know the learners' attitude towards forum online discussions. Four of the OFD participants were interviewed separately and the interviews were recorded and transcribed for analysis. The transcript was read carefully to find main themes and sub-themes. Finally the qualitative findings were interpreted and recommendations were made.

\subsection{Test Instrument}

As previously mentioned, the study used writing test in line with Level Exit Exam (LEE) format. The students were to write on the given topics for 40 minutes for the pretest and posttest. The participants should write argumentatively on the topics expressing arguments and counter-arguments or simply expressing their opinion on the topic.

\subsubsection{Writing Measure (Hirotani, 2009)}

The writing measure used in Hirotani's (2009) study was adapted for the data collection and analysis. Table 1 shows the writing measure, its main category, sub-category and measures (variables) which are the variables in the research questions in the quantitative phase of the study. The writing measure therefore measures the quantitative data collected from the pretest and posttest in relation to linguistic complexity of the EFL written output.

Table 1. Writing measure

\begin{tabular}{lll}
\hline Category & Subcategory & Measure \\
\hline \multirow{3}{*}{ Linguistic Complexity } & Lexical Diversity & Type $/ \sqrt{2 \times \text { Token }}$ \\
& Lexical Density & Type of contents words/tokens \\
& Syntactic Complexity & Number of clauses per T-Units \\
\hline
\end{tabular}

Linguistic complexity has been considered as important research variables in most of the applied linguistic researches (Housen \& Kuiken, 2009; Horatani, 2009; Tavakoli \& Foster, 2011) in measuring L2 performance and proficiency. According Housen and Kuiken (2009), complexity has thus been commonly characterized as ' $[\mathrm{t}]$ he extent to which the language produced in performing a task is elaborate and varied ..." (p. 2). Since the research objective is to know the linguistic complexity of the written performance of the EFL learners as a result of the OFD intervention, the writing measure (Hirotani, 2009) in Table 1 is valid for the purpose of the study.

\subsubsection{Linguistic Complexity}

Linguistic complexity consists of lexical diversity, lexical density and syntactic complexity. According Yu (2009) lexical diversity is defined as "one aspect of the quality of the product -as something to do with the range of vocabulary displayed in both written and spoken discourses." TTR (Type-token-ratio) and its different forms of calculation is the common way of measuring linguistic complexity (Yu, 2010; Hirotani, 2009). The one latest form of TTR used in the study by Hirotani (2009) is that Type $/ \sqrt{ } 2 \times N$ (token) in which total number of types were divided by the square root of the doubled tokens. Hirotani (2009) (citing Tajima, 2002) claims that by measuring lexical diversity in this manner, one can get more accurate result.

Lexical density is measured dividing the number of content words (nouns, verbs, adjectives and adverbs) by the total number of tokens (Johansson, 2008) as the lexical density is determined by the percentage of content words (Hirotani, 2009, Table 1). Total of words is the tokens and the total of different content words is the type. According to Johansson (2008) by measuring lexical density, we receive a notion of information packaging; a text with a high proportion of content words contains more information than a text with a high proportion of function words (prepositions, interjections, pronouns, conjunctions and count words). (p. 65)

According to Ortega (2003), Syntactic complexity is the range of forms that surface in language production and 
the degree of sophistication of such forms.' (p. 492). Syntactic complexity is measured to find out the effect of pedagogical intervention on the writing performance or ability of the learners. The syntactic complexity is generally measured by the mean number of clauses per t-units or sentences (Hirotani, 2009; Lu, 2008). A t- unit can be defined as the main clause and its subordinate clauses. Hunt (1965) described a t-unit as "one main clause with all subordinate clauses attached to it." (p. 20).

\subsubsection{Interview}

The interview enables the researcher to understand the learners' experiences and perceptions towards the use of online forum discussion in their EFL writing. Four participants (S1, S2, S3 \& S4) were selected for semi-structured interview based on their writing performance in the posttest ranging from excellent, moderate and poor respectively.

\subsection{Results of the Study: Findings and Analysis}

The following section describes the findings and analysis of quantitative data collected through posttest and followed by qualitative data collected through the interview.

Question $i$. Is there a significant difference in the lexical diversity between the written outputs of the OFD group and the blog group?

Table 2. Group statistics on the forum and blog lexical diversity

\begin{tabular}{lccccc}
\hline & OFD vs. Blog & $\mathrm{N}$ & $\mathrm{M}$ & $\mathrm{SD}$ & SEM \\
\hline Lexical Diversity & 1.00 & 28 & 4.17 & .62 & .12 \\
& 2.00 & 28 & 4.26 & .63 & .12 \\
\hline
\end{tabular}

Note: $\mathrm{N}=$ Number. $\mathrm{M}=$ Mean. $\mathrm{SD}=$ Standard Deviation. $\mathrm{SEM}=$ Standard Error Mean

Table 3. t-test results on the lexical diversity between the forum and the blog posttest results

\begin{tabular}{|c|c|c|c|c|c|c|c|c|c|c|}
\hline & \multicolumn{2}{|c|}{ LTEV } & \multicolumn{7}{|c|}{ t-test for Equality of Means } \\
\hline & & \multirow{2}{*}{ f } & \multirow{2}{*}{ Sig. } & \multirow{2}{*}{$\mathrm{t}$} & \multirow{2}{*}{ df } & \multirow{2}{*}{ *Sig. (2-td) } & \multirow{2}{*}{ MD } & \multirow{2}{*}{ SD } & \multicolumn{2}{|c|}{$95 \%$ CID } \\
\hline & & & & & & & & & Lower & Upper \\
\hline Lexical & Eq. var. assd & .21 & .65 & -.53 & 54 & .60 & -.09 & 17 & -.42 & .25 \\
\hline Diversity & Eq.var.not assd & & & -.53 & 54 & .60 & -.09 & .17 & -.42 & .25 \\
\hline
\end{tabular}

Note: ${ }^{*} p=0.5 . \mathrm{LTEV}=$ Levene's Test for Equality of Varience. SD $=$ Standard Deviation. $\mathrm{M}=$ Mean. Eq.var.assd. $=$ Equal varience assumed. $\mathrm{CID}=$ Confidence Interval of the difference. $\mathrm{td}=$ tailed.

The group statistics (Table 2) shows that the OFD group obtained a lower mean score $(\mathrm{M}=4.17, \mathrm{SD}=0.62)$ rather than the higher mean score of Blog asynchronous group $(\mathrm{M}=4.26, \mathrm{SD}=0.63)$. Levene's test for equality of variances revealed that the variability of the language diversity between the OFD and the blog conditions is the same ( $\mathrm{p}=0.65, \mathrm{p}>.05$ ). The $t$ test analysis (Table 3 ) has found that there is no significant difference between both the groups $\mathrm{t}(54)=-0.53, \mathrm{p}=0.59(\mathrm{p}>.05)$. These results suggest that the lexical diversity in the OFD writing and Blog writing is not statistically different from each other. 
Question ii. Is there a significant difference in the lexical density between the written outputs of the OFD group and the blog group?

Table 4. Group statistics on the forum and the blog lexical density

\begin{tabular}{lccccc}
\hline & OFD vs. Blog & N & M & SD & SEM \\
\hline Lexical density & 1.00 & 28 & .20 & .04 & .007 \\
& 2.00 & 28 & .20 & .04 & .007 \\
\hline
\end{tabular}

Note: $\mathrm{N}=$ Number. $\mathrm{M}=$ Mean. $\mathrm{SD}=$ Standard Deviation. $\mathrm{SEM}=$ Standard Error Mean.

Table 5. Statistical test on the lexical density between the forum and the blog posttest results

\begin{tabular}{|c|c|c|c|c|c|c|c|c|c|c|}
\hline & & \multicolumn{2}{|c|}{ LTEV } & \multicolumn{7}{|c|}{ t-test for Equality of Means } \\
\hline & & \multirow{2}{*}{$\mathrm{f}$} & \multirow{2}{*}{ Sig. } & \multirow{2}{*}{$\mathrm{t}$} & \multirow{2}{*}{ df } & \multirow{2}{*}{ *Sig. (2-td) } & \multirow{2}{*}{ MD } & \multirow{2}{*}{$\mathrm{SD}$} & \multicolumn{2}{|c|}{$95 \%$ CID } \\
\hline & & & & & & & & & Lower & Upper \\
\hline \multirow{2}{*}{$\begin{array}{l}\text { Lexical } \\
\text { density }\end{array}$} & Eq. var. assd & .70 & .41 & -.45 & 54 & .65 & -.01 & .01 & -.02 & .01 \\
\hline & Eq.var.not assd & & & -.45 & 54 & .65 & -.01 & .01 & -.02 & .01 \\
\hline
\end{tabular}

Note: $* p=0.5$. LTEV $=$ Levene's Test for Equality of Varience. SD = Standard Deviation. $\mathrm{M}=\mathrm{Mean}$. Eq.var.assd. $=$ Equal varience assumed. $\mathrm{CID}=$ Confidence Interval of the difference. $\mathrm{td}=$ tailed.

The group statistics (Table 4) shows that the OFD group $(\mathrm{M}=0.20, \mathrm{SD}=0.04)$ and the blog asynchronous group $(\mathrm{M}=0.20, \mathrm{SD}=0.04)$ have obtained an equal mean score of lexical density. Levene's test for equality of variances reveals that the variability of the lexical density between the OFD and the blog conditions is the same $(p=0.41$, $\mathrm{p}>.05$ ). The statistical analysis (Table 5) finds that there is no significant difference between both the groups $t(54)=-0.45, p=0.65(p>.05)$. These results suggest that the lexical density in the OFD writing and the blog writing is not statistically different from each other.

Question iii. Is there a significant difference in the syntactic complexity between the written outputs of the OFD group and the blog group?

Table 6. Group statistics on the forum and blog syntactic complexity

\begin{tabular}{lccccc}
\hline & OFD vs. Blog & $\mathrm{N}$ & $\mathrm{M}$ & $\mathrm{SD}$ & SEM \\
\hline Syntactic & 1.00 & 28 & .70 & .13 & .02 \\
Complexity & 2.00 & 28 & .66 & .13 & .02
\end{tabular}

Note: $\mathrm{N}=$ Number. $\mathrm{M}=$ Mean. $\mathrm{SD}=$ Standard Deviation. $\mathrm{SEM}=$ Standard Error Mean.

Table 7. Statistical test on the syntactic complexity between the forum and the blog posttest results

\begin{tabular}{|c|c|c|c|c|c|c|c|c|c|c|}
\hline & & \multicolumn{2}{|c|}{ LTEV } & \multicolumn{7}{|c|}{ t-test for Equality of Means } \\
\hline & & \multirow{2}{*}{$\mathrm{f}$} & \multirow{2}{*}{ Sig. } & \multirow{2}{*}{$\mathrm{t}$} & \multirow{2}{*}{$\mathrm{df}$} & \multirow{2}{*}{ *Sig. (2-td) } & \multirow{2}{*}{ MD } & \multirow{2}{*}{$\mathrm{SD}$} & \multicolumn{2}{|c|}{$95 \% \mathrm{CID}$} \\
\hline & & & & & & & & & Lower & Upper \\
\hline Syntactic & Eq. var. assd & .12 & .73 & 1.22 & 54 & .21 & .04 & .04 & -.03 & .11 \\
\hline Complexity & $\begin{array}{l}\text { Eq.var.not } \\
\text { assd }\end{array}$ & & & 1.22 & 54 & .21 & .04 & .04 & -.03 & .11 \\
\hline
\end{tabular}

Note: ${ }^{*} p=0.5$. LTEV $=$ Levene's Test for Equality of Varience. SD = Standard Deviation. $\mathrm{M}=\mathrm{Mean}$. Eq.var.assd. $=$ Equal varience assumed. $\mathrm{CID}=$ Confidence Interval of the difference. $\mathrm{td}=$ tailed. 
The group statistics (Table 6 ) shows that the OFD group obtained a slightly higher mean score $(\mathrm{M}=0.70, \mathrm{SD}=$ $0.13)$ than the higher mean score of the blog asynchronous group $(\mathrm{M}=0.66, \mathrm{SD}=0.13)$. Levene's test for equality of variances revealed that the variability of the syntactic complexity between the OFD and the blog conditions is the same $(p=0.73, p>.05)$. The statistical analysis (Table 7) finds that there is no significant difference between both the groups $t(54)=1.22, \mathrm{p}=0.21(\mathrm{p}>.05)$. These results suggest that the syntactic complexity in the OFD writing and the blog writing is not statistically different from each other.

\subsection{Summary and Discussion of Quantitative Data}

The analysis of posttest data between the OFD and the Blog (between the groups design) finds that there is no statistically significant difference between the OFD variables and the blog variables in terms of lexical diversity, lexical density syntactic complexity, lexical diversity and lexical density. However, the average syntactic complexity of the OFD group is more than the average of the blog group. The average (mean) of the lexical diversity and the lexical density is almost same in both the control and experimental groups. This shows that there is no significant difference between the writing performances of the OFD group and the blog group in terms of linguistic diversity, linguistic density and syntactic complexity with reference to the research objective and purpose of the study. The hypothesis therefore is accepted as a result of the quantitative findings and analysis.

\section{Question 2. What are learners' perceptions towards Online Forum Discussion?}

Four participants from treatment Group were interviewed using a semi-structured interview questions. The interviewees were selected based on their weak, average and strong performances in carrying out tasks. The interview was recorded and transcribed for analysis. The interviewees were coded as S1 (Student 1), S2 (Student 2), S3 (Student 3) and S4 (Student 4). As the interview with S4 was a brief one, the interview transcripts of S1, S2 \& S3 are analyzed in detail, and the data from S4 were used briefly. The qualitative data analysis found four main themes that are summarized in Table 8. The analysis was carried out using Framework method (Heath, et al. 2013) of interview analysis, and NVivo, 2010 (a qualitative data analysis computer software package). In the Framework method, two persons (researcher and the co-teacher) go through the transcripts and code them. Later the codes are discussed and agreed for inter-coder reliability. The NVivo, 2010 has been very helpful in organizing the data under different themes (codes) and sub-themes. Table 8 depicts the main themes and sub-themes that are found in the interview data analysis. The content is summarized and discussed in the section that follows Table 8 .

Table 8. Themes and sub-themes from qualitative data analysis for online forum discussions group

\begin{tabular}{|c|c|c|c|}
\hline $\begin{array}{l}\text { SI } \\
\text { No. }\end{array}$ & $\begin{array}{l}\text { Main } \\
\text { theme/criteria }\end{array}$ & Sub-themes & What OFD subjects say \\
\hline \multirow[t]{5}{*}{1} & \multirow[t]{5}{*}{ Feeling } & Happy & "I feel very happy...." (S3) \\
\hline & & & "I miss this class, and I happy to work." (S1) \\
\hline & & Gratefulness \& likeness & $\begin{array}{l}\text { "I am grateful to the persons who gave us the chance to } \\
\text { use these types of writing." (S2) }\end{array}$ \\
\hline & & Comfortable & "I feel comfortable, and I feel pleasure..."(S2) \\
\hline & & Pleasure & "I feel comfortable, and I feel pleasure..." (S2) \\
\hline \multirow[t]{6}{*}{2} & \multirow{6}{*}{$\begin{array}{l}\text { Aspects of } \\
\text { Motivation }\end{array}$} & Newness & "when you ask me one question 'what's your favorite \\
\hline & & & days in a week?'I said Wednesday because I have online \\
\hline & & & "we used another twe of writing " (S2) \\
\hline & & & "It's a smart idea for us" (S1) \\
\hline & & Beneficial & "I will get benefits." (S2) \\
\hline & & & "I know that it's good for me" (S3) \\
\hline
\end{tabular}


3 Interaction

4
Peer -interaction
Discussion

Exchange of ideas or information

Mutual respect

Ideas

- brainstorming

Organization

easier than paper and pencil

Carefulness

Spelling

Self-correction/computer check

-better correction with paper and pencil.

grammar
" ask my friends about "(S3)

"when we discuss about....discussion about any topic" (S3)

"get many information with different people" (S3)

"we need to exchange our ideas" (S2)

“....using the nice language that we can use to

communicate with others, we respect others, how we can reply because we exchange ideas, information; take and we give at the same time." (S2)

"And we learn how can I answer when another student give me idea; and respect, when I answer I respect him idea." (S1)

“...we respect others, how we can reply because we exchange ideas, information; take and we give at the same time.” (S2)

"Sometime my point is different for another people."

(S2)

"I give my attention to the idea; of the writing electronic... because we are sharing our idea during the writing online..." (S4)

"we compare for our point, for another people; that's good for me and good for them" (S3)

"The idea we need to share our ideas with others;", (S2)

“...they do not know how to organization their ideas, and which time use...time like this in the class to write.." (S3)

"when they see what other students write, they take care about how they can use the language while writing how we can take care about the spelling." (S2)

"I improved first thing is my spelling because when I wrote in keyboard.. when I wrote in key board... wrote letter by letter, and I must know the full spelling of the word" (S1)

"my laptop in my class also tell me if I have spelling mistakes, giving me red lines... enter that word.” (S1) “...even automatically sometimes the computer give us some hints that you have mistakes or error in the spelling." (S2)

“... the grammar too. We need to take care to know the 
authenticity/originality

Self study

Technical

slow network

system failure

number of computers

or labs.

Typing

Time

Topic and Ideas suitable, and to get the full sentence without any grammatical mistakes." (S1)

"I make attention online writing more than the paper because when I... "while I writing the keyboard, I take care about the grammar, I take care about the spelling.."(S2)

"wrote good grammar because when I wrote good grammar, another student must understand me and replying to me. If I used..maybe..ah..spellingmistakes..maybe..they don't understand me, and they don't reply with me." (S3) “when I wrote for online discussion I'm open, not limit when we write. They are original writing, they are your opinion original.. " (S1)

“..sometimes I search in the website to get the information"

"Sometimes the computer is not working, and stuck.."

"the system for the computer works slowly..." (S3)

"I think the main problem with the signals, the network. It's slow."

"there are not enough labs (computers) for all the students in our sections." (S2)

"there are not enough computers for classmates." (S1)

"we have problem with finding a free lab to have the online discussion....some time." (S4)

"sometimes it's difficult to write in keyboard. For example speed in writing"

"when I type on computer I am not perfectly when I type in keyboard." (S1)

“... sometimes, I don't have time for replying with my students or classmates" (S1)

"when I wrote or when I read for another student give us good idea, and I want to reply to them, but I can't reply to them because no enough time.." (S1)

“, I don't have time for replying with my students or classmates I go back to home and use my iphone to reply to them. That's very easy for me." (S1)

"we face difficulties to understand the topic; ... if we don't understand the topic, how can you answer that 


question." (S4)
"I find difficulty how I reply to other students' (posting).
Because they have difficult or different idea." (S2)
"I cannot convey them easily because it will be some
aggressive way that we will reply. For that I feel that I
peed to have some polite way to communicate with
them." (S3)
there aren't enough time for replying with all students
because you want us just for group may three students
or two students. And my group some time don't give us a
specific idea; and when I wrote or when I read for
another student give us good idea, and I want to reply to
them, but I can't reply to them because no enough
time...(S3)
Yeah..I want many topics that topics different for the
boys and girls, not focus only for the girls (S3)

\subsection{Summary and Discussion of Qualitative Data}

A careful thematic analysis of the interview has identified seven major themes or dimensions of the online forum discussions with their sub-themes. They are: 1) feeling (Table 8, point 1) containing the sub-themes such as happiness, comfort, gratefulness and pleasure; 2) motivation (Table 8, point 2) containing sub-themes such as benefits and newness; 3 ) interaction (Table 8 , point 3 ) with the sub-themes such as peer interaction, discussion, exchange of ideas, and mutual respect; 4) writing skills (Table 8, point 4) such as brainstorming ideas, organization, carefulness, spelling and originality of writing; 5) autonomy (Table 8, point 5) containing self-study as the sub-theme; 6) challenges (Table 8, point 8) containing technical, typing, timing, topic, presentation and grouping; and 7) cultural issues (Table 8, point 7. Each sub-theme is derived from the interview excerpts which are quoted verbatim against each one (Table 8).

The feeling refers to what and how the subjects felt about the online forum discussions. This includes the sub-themes such as happiness, gratefulness and likeness, comfort and pleasure towards the process of the online forum discussions (OFDs). For example the students said; "...I feel very happy..." (S3), "I am grateful to the persons who gave us the chance to use these types of writing." (S2), "comfortable"(S2) or "I feel pleasure"(S2), etc.

The Motivational aspects of OFD are sub-themed as newness and benefits. The learners found that the newness of the OFD in writing in comparison with traditional paper and pencil writing has motivated them, and the OFDs are beneficial to their career. Students said: "we used another type of writing." (S2)and "It's a smart idea for us" (S1). Moreover, most learners are interested in the use of electronic devices such as computers, laptops, tablets and smart phones; and their likeness for using these gadgets is yet another source of their motivation in OFD. In addition, they have been given specific time to complete each OFD session, and the students' eagerness to attend the OFD sessions is also an evidence for their interest and motivation in the discussion. For example "when you ask me one question 'what's your favorite days in a week?' I said Wednesday because I have online discussion."(S1).

The next important major theme of the OFD found in the interviews is the interaction. The learner-learner interaction is the outstanding feature of the OFDs. Peer interaction and discussion played a major role in the OFDs in promoting their writing. This also helped them exchange ideas with mutual respect. The students said;" ask my friends about ........." (S3), "when we discuss about....discussion about any topic" (S3), "..ask my friends about ..."(S3), and "we respect others"(S2). This interaction leads to the students' acquiring more knowledge through sharing different information on topics unlike individual learning. For example they said: "we get many information."(S3) and "we need to exchange our ideas" (S2). 
This also help learners in their self study skills as they get opportunities to receive ideas or information from their peers as one of the interviewees said; we exchange ideas, information; take and we give at the same time." (S2)

Along with these, the analyze of the qualitative data revealed that the OFDs did help their writing skills in brainstorming ideas, organization, carefulness, spelling, correction, grammar, and the authenticity/originality of the writing. "I give my attention to the idea; of the writing electronic... because we are sharing our idea during the writing online..." (S4), "know how to organization their ideas, and which time use...time"(S3), when I wrote in key board...wrote letter by letter, and I must know the full spelling of the word" (S1), "when they see what other students write, they take care about how they can use the language while writing how we can take care about the spelling." (S2), "automatically sometimes the computer give us some hints that you have mistakes or error in the spelling." (S2),. "wrote good grammar because when I wrote good grammar, another student must understand"(S3). The learners also felt that their writing is more purposeful and authentic in the OFDs. For instance, "They are original writing, they are your opinion original." (S1).

Learners in online forum discussion are exposed to diverse study skills in terms of their autonomy in learning. For example, S2 says "..sometimes I search in the website to get the information"(S2). This reveals that the OFDs can promote self study or autonomous learning among the participants.

The interview data analysis found that the OFD has its own difficulties and challenges as yet another major theme. Students faced technical difficulties such as slow network, system failure and no lab or computer availability as students said: "Sometimes the computer is not working, and stuck.."(S1), "...works slowly."(S3).In addition, they faced technical challenges, typing (keyboard usage), timing, topic and ideas, difficulty in presenting their ideas in group and grouping. The students said: "Sometimes the computer is not working, and stuck.."(S1), "it's difficult to write in keyboard. For example speed in writing" (S1), "I don't have time for replying with my... classmates",(S1), "we face difficulties to understand the topic..(S4),"some aggressive way that we will reply"(S3), "my group some time don't give us a specific idea"(S3)and "and when I wrote or when I read for another student give us good idea, and I want to reply to them, but I can't reply to them ...(S3); Students finds difficulty in locating their group participants' post as the posts from all the participants are displayed as a single thread. Moodle does not have the option of the grouping a batch of students into groups of 3 or 4 . Another issue noticed is that of cultural that some students felt uncomfortable in the OFD with opposite sexes. It has got to do with the cultural background of the learners, "I want many topics that topics different for the boys and girls.." (S3)

\subsection{Limitation of the Study}

The study was limited to 56 EFL students of Arab background. The participants are from semi-urban social context. The study lasted only for a one semester i.e. about 10 weeks. The objective of the study was to find out the effectiveness of the online forum discussion on the participants' EFL writing $o$ in terms of linguistic complexity. The setting of the study was limited to the college campus. The study therefore has its own limitations. The study did not consider the demography of the participants whether it could affect the outcomehow the writing performance of female students differs from the writing performance of the male students. The social and cultural implications of the treatment were not considered in the study. The study in a different setting, with more number of participants for a longer period of time may bring out different results.

\section{Recommendations and Conclusion}

The research revealed that the OFD mediated writing treatment has no statistically significant effect on the EFL learners' writing performance in terms the linguistic complexity of the written output. However, the qualitative data collected through interview provided rich source of information about the significance of online forum discussion on various aspects of learners' views, feelings and attitudes towards the same. The students expressed a very positive attitude towards the use of online forum discussions in English Language Teaching and Learning (ELTL). The communicative or interactive feature of the OFD distinguished it from the blog writing which is carried out asynchronously without student to student interaction. In the OFDs, the learners are conscious of other members reading their ideas, seeing their possible grammatical or spelling errors, etc. on a real-time basis unlike blog writing which is carried out individually. Along with other themes of the interview data analysis and findings, students' motivation to participate more in ICT integrated writing sessions underlines the need for incorporating ICT tools in EFL lessons especially in the Middle East.

The findings of the study revealed that the online forum discussions can be incorporated as a best practice in ELT if implemented effectively. In this regard, the teachers should make clear the ground rules for the discussion including strict use of L2, refraining from silly jokes and insults; the criteria of evaluation of the forum 
discussion should be clearly communicated to students, so that they know what is expected of them in the process such as number of posts, the sentences, etc. Topics of interest and relevance, which challenge the learners' thinking, should be assigned for the discussion in stress free atmosphere which would effectively engage the learners in discussions ("Using Online Discussions", 2011).

To conclude, the findings of the study highlighted the significance of online forum discussions in facilitating English language learning, and the need for the stakeholders and educational institutions to promote the use of such ICT tools in ELT in the Middle East in general and Oman in particular. They should install and maintain well-equipped learning management system with effective infrastructures and facilities. Teachers and students should be trained in the use of technology in this regard. ICT tools are going to be inevitable in ELT, and the study and its findings emphatically state the need for effectively implementing synchronous online forum discussions for promoting EFL writing.

\section{References}

Al-Aufi \& Al-Azri, (2013). Information literacy in Oman's higher education: A descriptive-inferential approach. Sultan Qaboos University. Department of Information studies. http://dx.doi.org/10.1177/0961000613486824

Bangert, A. W. (2004). The seven principles of good practice: a framework for evaluating on-line teaching. The Internet and Higher Education, 7(3), 217-232. http://dx.doi.org/10.1016/j.iheduc.2004.06.003

Beal, V. (2010). All About Online Forums. Retrieved October 6, 2013, from http://www.webopedia.com/DidYouKnow/Internet/2008/forum_etiquette.asp

Boud, D. (2001). Using journal writing to enhance reflective practice. New Directions for Adult and Continuing Education, 20, 9-17. http://dx.doi.org/10.1002/ace.16

Boyle, J. T., \& Nicol, D. J. (2003). Using classroom communication systems to support interaction and discussion in large class settings. Association for Learning Technology Journal, 11(3), 43-57. http://dx.doi.org/10.1080/0968776030110305

Cavana, M. (2009). Closing the circle: from Dewey to web 2.0. In C. Payne (Ed.), Information technology and constructivism in higher education: Progressive learning frameworks (pp. 1-13), IGI Global, Hershey, PA. http://dx.doi.org/10.4018/978-1-60566-654-9.ch001

Chang, C. F. (2012). Fostering EFL College Students' Register Awareness: Writing Online Forum Posts and Traditional Essays. International Journal of Computer-Assisted Language Learning and Teaching (IJCALLT), 2(3), 17-34. http://dx.doi.org/10.4018/ijcallt.2012070102

Chao, K. J., Hung, I. C., \& Chen, N. S. (2012). On the design of online synchronous assessments in a synchronous cyber classroom. Journal of Computer Assisted Learning, 28(4), 379-395. http://dx.doi.org/10.1111/j.1365-2729.2011.00463.x

Cole, J., \& Foster, H. (2008). Using Moodle - Teaching with the popular open source course management system, O.R. Media, Editor: United Sates of America. Comparative experiments. (n.d.). McGraw-Hill Dictionary of Scientific and Technical Terms. Retrieved November 30, 2013, from http://www.answers.com/topic/comparative- experiments

Costa, C., Alvelos, H., \& Teixeira, L. (2012). The Use of Moodle e-learning Platform: A Study in a Portuguese University. Procedia Technology, 5, 334-343. http://dx.doi.org/10.1016/j.protcy.2012.09.037

Dixson, M. D. (2012). Creating effective student engagement in online courses: What do students find engaging? Journal of the Scholarship of Teaching and Learning, 10(2), 1-13.

Fitze, M. (2006). Discourse and participation in ESLface-to-face and written electronic conferences. Language Learning \&Technology 10(1), 67e86. Retrieved from http://lt.msu.edu/vol10num1/pdf/fitze.pdf

Graham, C., Cagiltay, K., Lim, B., Craner, J., \& Duffy, T. M. (2001). Seven principles of effective teaching: a practical lens for evaluating online courses. Technology Source, 30(5).

Gold, S. (2001). A constructivist approach to online training for online teachers. Journal of Asynchronous Learning Networks, 5(1), 35-57.

Harris, N., \& Sandor, M. (2007). Developing online discussion forums as student centredpeerlearning environments. Proceedings ascilite Singapore 2007: Concise paper. Retrieved October 5, 2013, from http://www.ascilite.org.au/conferences/singapore07/procs/harris.pdf 
Hastie, M., Hung, I. C., Chen, N. S., \& Kinshuk. (2010). A blended synchronous learning model for educational international collaboration. Innovations in Education and Teaching International, 47(1), 9-24. http://dx.doi.org/10.1080/14703290903525812

Hirotani, M. (2009). Synchronous Versus Asynchronous CMC and Transfer to Japanese Oral Performance. CALICO Journal, 26(2).

Hou, H-T., \& Wu, S-Y. (2011). Analyzing the social knowledge construction behavioral patterns of an online synchronous collaborative discussion instructional activity using an instant messaging tool: A case study. Computers \& Education, 57(2), 459-1468. http://dx.doi.org/10.1016/j.compedu.2011.02.012

Housen, A., \& Kuiken, F. (2009). Complexity, accuracy, and fluency in second language acquisition. Applied Linguistics, 30(4), 461-473. http://dx.doi.org/10.1093/applin/amp048

Hunt, K. (1965). Grammatical structures written at three grade levels. NCTE Research report No. 3. Champaign, IL, USA: NCTE Retrieved from http://files.eric.ed.gov/fulltext/ED113735.pdf

Johansson, V. (2008). Lexical diversity and lexical density in speech and writing: a develop- mental perspective. Working Papers, 53, 61-79.

Johnson, S. D., \& Aragon, S. R. (2003). An Instructional Strategy Framework for Online Learning Enviroments.

Johnson, G. (2008). The relative learning benefits of synchronous and asynchronous text-based discussion. British Journal of Educational Technology, 39, 166-169.

Kear, K. L., \& Heap, N. W. (2007). Sorting the wheat from the chaff: investigating overload in educational discussion systems. Journal of Computer Assisted Learning, 23(3), 235-247. http://dx.doi.org/10.1111/j.1365-2729.2006.00212.x

Kelly, B. (2014). Synchronous and Asynchronous Learning: 15 Strategies for engaging Online Students Using Real-time Chat, Threaded Discussions and Blogs.

Kim, K. (2012). L2 Phone-based interaction (PBI) and Development of Communicative competence: A Case Study of An Adult's English Learning in EFL context. Asian EFL Journal, 14 (3).

Lu, X. (2008). Automatic Measurement of Syntactic Complexity in SLA.

Miyazoea, T., \& Anderson, T. (2012). Discuss, reflect, and collaborate: A qualitative analysis of forum, blog, and wiki use in an EFL blended learning course. Procedia-Social and Behavioural Sciences, 34, 146-152. http://dx.doi.org/10.1016/j.sbspro.2012.02.030

Oztok, M., Zingaro, D., Brett, C., \& Hewitt, J. (2012). Exploring asynchronous and synchronous tool use in online courses. Computers \& Education, 60(1), 87-94. http://dx.doi.org/10.1016/j.compedu.2012.08.007

Rouse, M. (2011). Definition: Discussion board (discussion group, message board, online forum).

Rovai, A. P. (2007). Facilitating online discussions effectively. The Internet and Higher Education, 10(1), 77-88. http://dx.doi.org/10.1016/j.iheduc.2006.10.001

Savignon, S. J., \& Roithmeier, W. (2004). Computer-mediated communication: texts and strategies. The CALICO Journal, 21(2), 265-290.

Schwarz, B. B., \& Asterhan, C. S. C. (2011). E-moderation of synchronous discussions in educational settings: A nascent practice. Journal of the Learning Sciences, 20, 395-442. http://dx.doi.org/10.1080/10508406.2011.553257

Scherer- Bassani, P. B. (2011). Interpersonal exchanges in discussion forums: A study of learning communities in $\begin{array}{lllll}\text { distance learning settings. Computers \& } & \text { Education, } & \text { 56(4), } & \text { 931-938. }\end{array}$ http://dx.doi.org/10.1016/j.compedu.2010.11.009

Shaw, R. S. (2012). The relationships among group size, participation, and performance of programming language learning supported with online forums. Computers \& Education, 62, 196-207. http://dx.doi.org/10.1016/j.compedu.2012.11.001

Tavakoli, P., \& Foster, P. (2011). Task design and second language performance: the effect of narrative type on learner output. Language Learning, 61(s1), 37-72. http://dx.doi.org/10.1111/j.1467-9922.2011.00642.x

Teng, D. C., Chen, N., Kinshuk, S., \& Leo, T. (2012). Exploring students' learning experience in an international online research seminar in the Synchronous Cyber Classroom. Computers \& Education, 58(3)918-930. http://dx.doi.org/10.1016/j.compedu.2011.10.018 
Using Online Discussion Boards to Enhance Learning in Your Class (2011, April 21). Retrieved from $\mathrm{http}$ //depts.washington.edu/swedtech/2011/04/21/using-online-discussion-boards-to-enhance-learning-in-y our-class/

Xia, C., Fielder, J., \& Siragusa, L. (2013). Achieving better peer interaction in online discussion forums: A reflective practitioner case study. Issues in Educational Research, 23(1), 97-113.

Yu, G. (2010). Lexical diversity in writing and speaking task performances. Applied linguistics, 31(2), $236-259$. http://dx.doi.org/10.1093/applin/amp024

\section{Appendix A}

\section{Coded chart for data collection}

\begin{tabular}{|l|l|l|l|l|}
\hline Participant's name:................ & Participants' code & \\
\hline Category & Sub-category & Measure/Variable & Code & Number \\
\hline \multirow{4}{*}{$\begin{array}{l}\text { Linguistic } \\
\text { Complexity }\end{array}$} & Lexical Diversity & Type/ $\sqrt{2} \times$ Token $(104 / \sqrt{2} \times 301)$ & LDv & 4.24 \\
\cline { 2 - 5 } & Lexical Density & Type of content words/tokens $(57 / 301)$ & LDn & 0.189 \\
\cline { 2 - 5 } & Syntactic complexity & Number of clauses per T-Unit $(29 / 40)$ & SCx & 0.72 \\
\hline
\end{tabular}

\section{Appendix B}

Coded Data for analysis

\begin{tabular}{|c|c|c|c|c|c|c|c|}
\hline \multicolumn{8}{|c|}{ Coded Row Data: OFD Posttest\& Blog posttest } \\
\hline \multicolumn{4}{|c|}{ Synchronous OFD } & \multicolumn{4}{|c|}{ Asynchronous Blog } \\
\hline Participants & LD2 & LDn2 & SCx2 & Participants & LD2 & LDn2 & $\mathrm{SCx} 2$ \\
\hline S1 & 4.24 & 0.18 & 0.72 & S1 & 3.8 & 0.18 & 0.46 \\
\hline $\mathbf{S 2}$ & 3.52 & 0.18 & 0.73 & $\mathbf{S 2}$ & 3.36 & 0.17 & 0.73 \\
\hline S3 & 4.26 & 0.18 & 0.86 & S3 & 4.9 & 0.22 & 0.64 \\
\hline S4 & 3.66 & 0.15 & 0.63 & S4 & 4.29 & 0.18 & 0.86 \\
\hline S5 & 4.48 & 0.18 & 0.72 & S5 & 4.39 & 0.22 & 0.57 \\
\hline S6 & 4.64 & 0.18 & 0.7 & S6 & 4.58 & 0.23 & 0.67 \\
\hline S7 & 4 & 0.21 & 0.77 & S7 & 3.73 & 0.16 & 0.6 \\
\hline S8 & 3.68 & 0.18 & 0.875 & S8 & 3.78 & 0.17 & 0.59 \\
\hline S9 & 3.49 & 0.16 & 0.78 & S9 & 4.77 & 0.25 & 0.4 \\
\hline S10 & 4.62 & 0.2 & 0.73 & S10 & 4.45 & 0.21 & 0.62 \\
\hline S11 & 2.98 & 0.18 & 0.81 & S11 & 4.66 & 0.2 & 0.65 \\
\hline S12 & 3.78 & 0.22 & 0.74 & S12 & 4.87 & 0.22 & 0.58 \\
\hline S13 & 4.46 & 0.23 & 0.45 & S13 & 4.18 & 0.27 & 0.54 \\
\hline S14 & 5.8 & 0.28 & 0.6 & S14 & 3.81 & 0.17 & 0.83 \\
\hline S15 & 3.78 & 0.16 & 0.71 & S15 & 3.43 & 0.18 & 0.39 \\
\hline S16 & 3.21 & 0.15 & 0.62 & S16 & 4.02 & 0.24 & 0.64 \\
\hline S17 & 4.43 & 0.25 & 0.68 & S17 & 4.93 & 0.21 & 0.68 \\
\hline S18 & 3.41 & 0.18 & 0.55 & S18 & 4.88 & 0.21 & 0.7 \\
\hline
\end{tabular}




\begin{tabular}{|l|c|c|c|c|c|c|c|}
\hline $\mathbf{S 1 9}$ & 5.13 & 0.24 & 0.77 & $\mathbf{S 1 9}$ & 4.15 & 0.17 & 0.75 \\
\hline $\mathbf{S 2 0}$ & 4.76 & 0.19 & 0.75 & $\mathbf{S 2 0}$ & 3.28 & 0.14 & 0.72 \\
\hline $\mathbf{S 2 1}$ & 4.14 & 0.2 & 0.83 & $\mathbf{S 2 1}$ & 4.93 & 0.25 & 0.8 \\
\hline $\mathbf{S 2 2}$ & 4.29 & 0.172 & 0.91 & $\mathbf{S 2 2}$ & 3.66 & 0.13 & 0.72 \\
\hline $\mathbf{S 2 3}$ & 4.22 & 0.2 & 0.79 & $\mathbf{S 2 3}$ & 3.56 & 0.17 & 0.42 \\
\hline $\mathbf{S 2 4}$ & 3.91 & 0.18 & 0.6 & $\mathbf{S 2 4}$ & 4.79 & 0.26 & 0.71 \\
\hline $\mathbf{S 2 5}$ & 4.28 & 0.19 & 0.72 & $\mathbf{S 2 5}$ & 5.53 & 0.22 & 0.77 \\
\hline $\mathbf{S 2 6}$ & 4.92 & 0.25 & 0.42 & $\mathbf{S 2 6}$ & 4.99 & 0.25 & 0.89 \\
\hline $\mathbf{S 2 7}$ & 4.81 & 0.273 & 0.416 & $\mathbf{S 2 7}$ & 3.15 & 0.14 & 0.76 \\
\hline $\mathbf{S 2 8}$ & 3.8 & 0.16 & 0.69 & $\mathbf{S 2 8}$ & 4.3 & 0.21 & 0.7 \\
\hline
\end{tabular}

\section{Appendix C}

\section{Screen shots of Synchronous OFD instructions and Discussions}
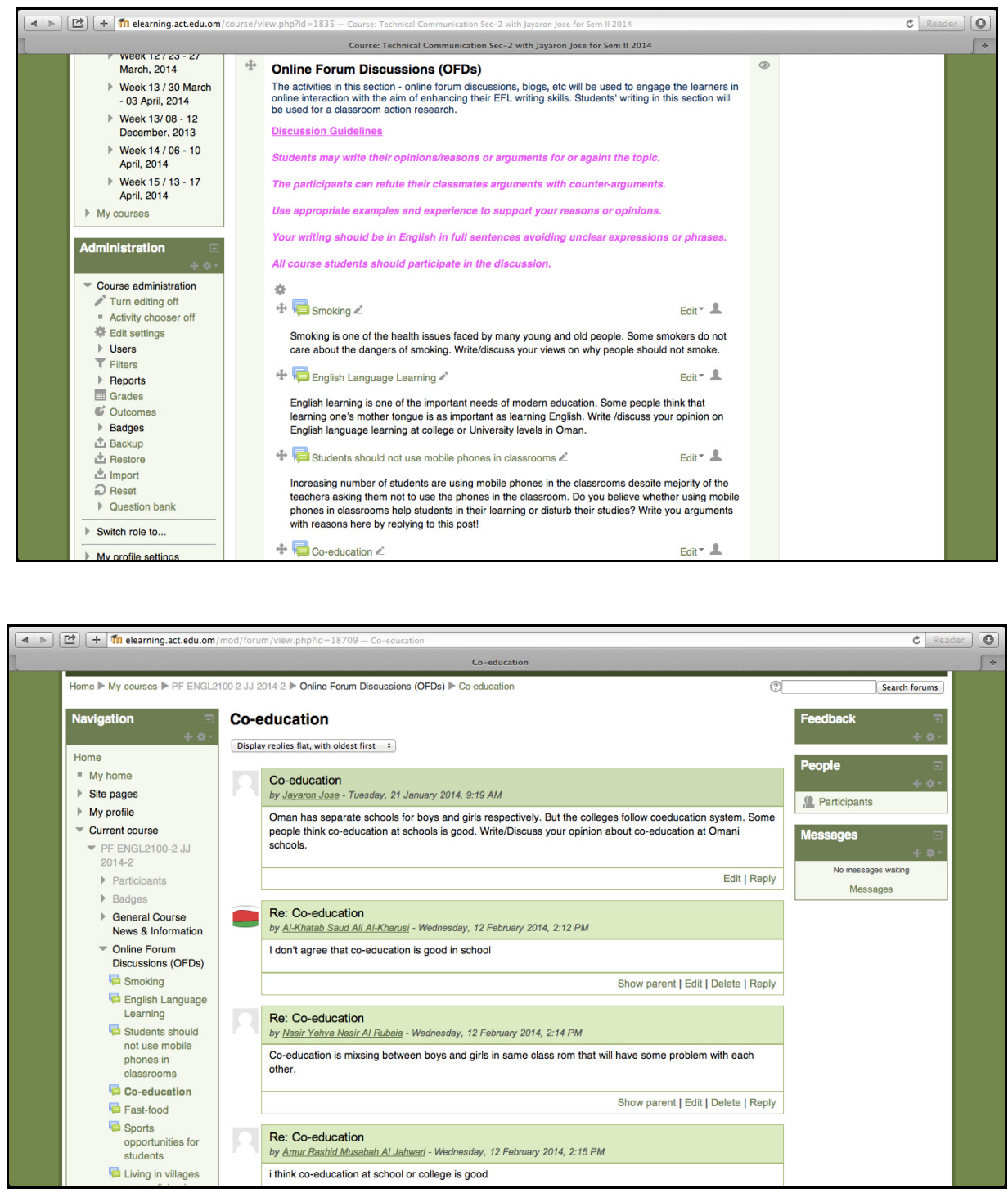


\section{Appendix D}

\section{Sample asynchronous blog writing}

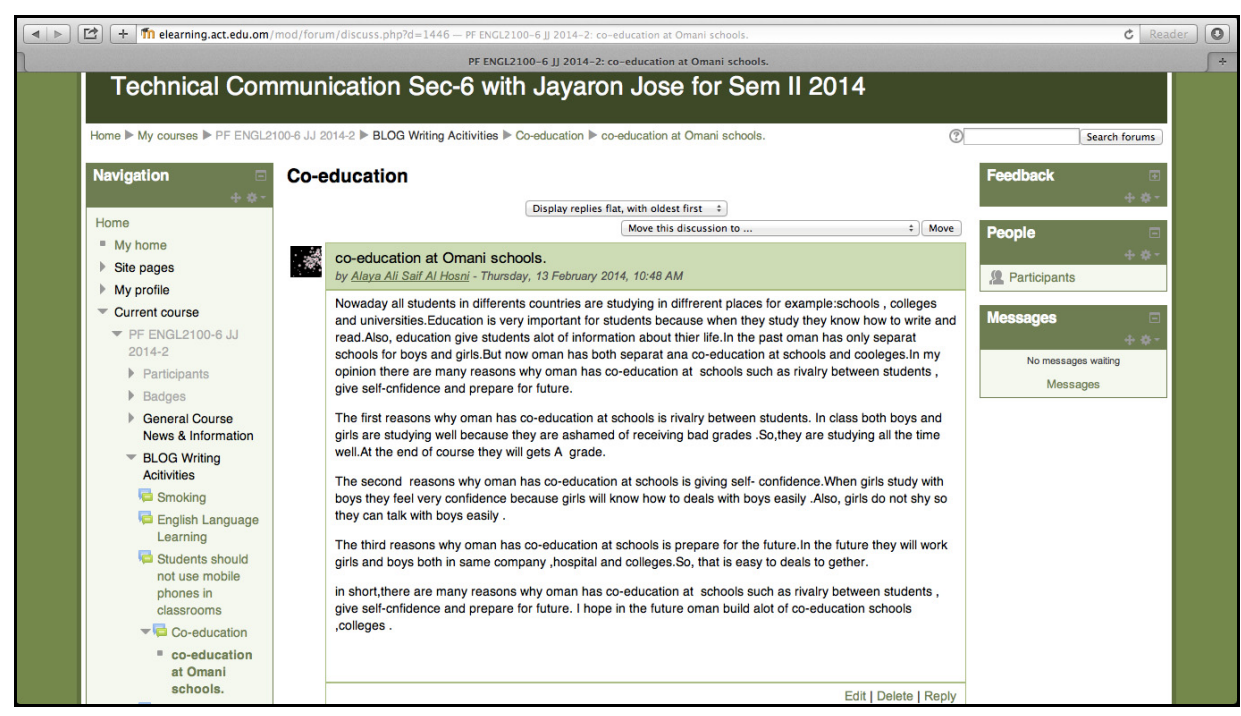

\section{Appendix E}

\section{Sample students' writing (ttests)}

Section (2)
Write persuasively on the following topic.
Write as much as possible. (A five paragraph essay is ideal) 50 min.
TOPIC: Mobile phone usage by students in classrooms is on increase. Some teachers insist on students' not
using mobile phones in classes, but some teachers and students find that using mobile phones in
classrooms has many advantages. Write/discuss your opinion on the use of mobile phones in the
classrooms.

- Mobile phone become (35) second mother for almask all people. Day by day technology become more deulop and peaple like to change to hew things. Howeses, the most popular techology for the people is mobile phone. All people nwaday use mobile phon. I am not agree with people why use mobile phone at classrooms for three resons such as: disturbing, wasting the time, and confusing.

The most important reason of using mobile phone at classrooms is disturbing the class. Actully when student ane using mobile phone at the classraoms the 7 make some noisy and being busy arith thair mabile phone. Then they 2 disturbing their classmate about what thay ane daing. For example they 2 surf the interinet and search a bout the vedio thep they will show it
for har his dassmate. The second most im portant reason of using mobile phone s westing the 


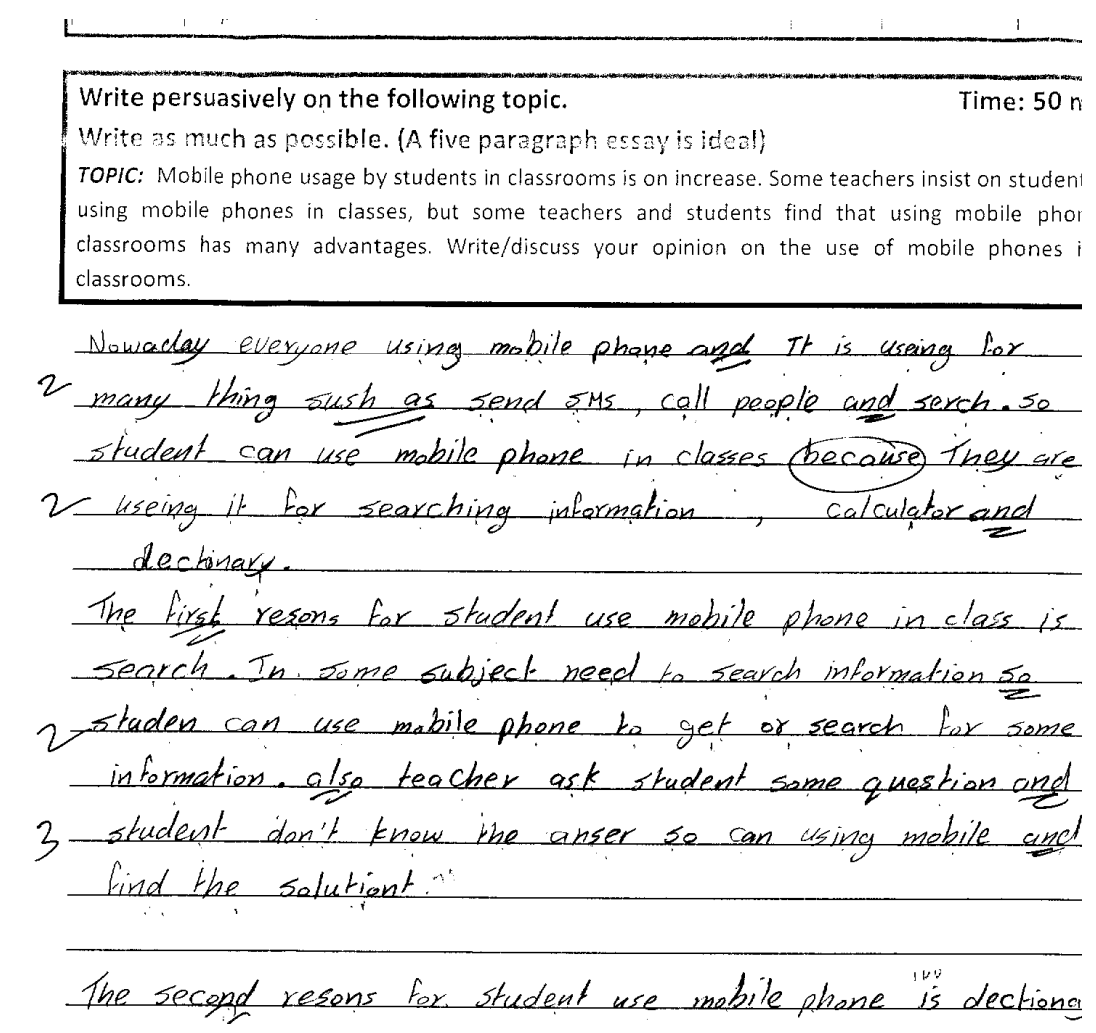

\section{Copyrights}

Copyright for this article is retained by the author(s), with first publication rights granted to the journal.

This is an open-access article distributed under the terms and conditions of the Creative Commons Attribution license (http://creativecommons.org/licenses/by/3.0/). 